\title{
Stress tolerance of Xerocomus badius and its promotion effect on seed germination and seedling growth of annual ryegrass under salt and drought stresses
}

\author{
Binghua Liu ${ }^{1,2+} \mathbb{D}$, Xinghong Liu ${ }^{1+}$, Fangchun Liu ${ }^{1,3^{*}}$, Hailin Ma ${ }^{1,3^{*}}$, Bingyao Ma ${ }^{1,3}$ and Lin Peng ${ }^{1}$
}

\begin{abstract}
Comparative evaluations were conducted to assess the effects of different $\mathrm{pH}$ levels, $\mathrm{NaCl}$-induced salt stress, and PEG-induced drought stress on the mycelial growth of Xerocomus badius. The results showed that $X$. badius mycelium grew well at a wide $\mathrm{pH}$ range of $5.00 \sim 9.00$. Although the mycelium remained viable, mycelial growth of $X$. badius was significantly inhibited with increasing salt and drought stresses. Furthermore, a soilless experiment in Petri dishes was performed to investigate the potential of $X$. badius to induce beneficial effects on seed germination and seedling growth of annual ryegrass (Lolium multiflorum Lam.) under salt and drought stresses. Seed priming with X. badius enhanced the seedling growth of L. multiflorum Lam. under NaCl-induced salt stress and PEG-induced drought stress. However, $X$. badius did not significantly improve the seed germination under non-stress and mild stress conditions. It suggested that $X$. badius inoculation with seeds was not essential for seed germination under non-stress and mild stress conditions, but contributed highly to seedling growth under severe stress conditions. Therefore, seed priming with $X$. badius on ryegrass could be an effective approach to enhance plant tolerance against drought and salt stresses. $X$. badius could be a good candidate for the inoculation of ectomycorrhizal plants cultivation programs in mild saline and semiarid areas.
\end{abstract}

Keywords: Drought stress, Mycelium growth, Salt stress, Seed germination, Seedling growth, Xerocomus badius

\section{Introduction}

Abiotic and biotic stresses influence plant growth, survival and productivity. Drought and high salinity are the two most important environmental factors that negatively affect seed germination, seedling growth and development, and ultimately influence crop yield, food quality and global food security. Application of stress tolerant plant growth promoting fungi (PGPF) may enhance crop seed germination, seedling establishment, plant growth, and productivity under adverse environmental

\footnotetext{
*Correspondence: fchliu@126.com; mahlin@163.com

${ }^{\dagger}$ Binghua Liu and Xinghong Liu contributed equally to this paper

1 Shandong Academy of Forestry, 42, East Wenhua Road, Shandong

250014 Jinan, China

Full list of author information is available at the end of the article
}

conditions (de Zelicourt et al. 2013; Guerrero-Galán et al. 2019; Hossain et al. 2017; Kumar and Verma 2018; Tomer et al. 2016; Vijayabharathi et al. 2016; Vimal et al. 2017; Yan et al. 2019).

Mycorrhizal fungi are one of the commonly occurring microorganisms in soil, and more than $80 \%$ of land plants naturally establish mutualistic symbiotic relationships with these fungi (Bonfante and Genre 2010). Mycorrhizal fungi play an increasing vitally important role in host plants growth promotion, in inducing plant stress tolerance and agricultural sustainability under various environmental stress conditions (Behie and Bidochka 2014; Bonfante and Genre 2010; Courty et al. 2010; Garcia et al. 2016; Hossain et al. 2017; Javeria et al. 2017; Shen et al. 2018; Yan et al. 2019). 
Ectomycorrhizal (ECM) fungi, about 7000 to 10,000 species in the world, play a vital role in plants nutrient cycle by establishing mutual symbiosis with plants' roots (Becquer et al. 2019; Cairney 2012; Taylor and Alexander 2005). Application of the beneficial mycorrhizal fungi in agricultural practices promises to be a fundamental tool for sustainability of crop production (Owen et al. 2015; Prasad et al. 2016; Tomer et al. 2016). In order to develop controlled ectomycorrhization practices that are suitable for the inoculation of field plants and are efficient in promoting host plants' growth under specific environmental conditions, it is necessary to isolate potential ECM fungi and evaluate their biological, physiological and symbiotic characteristics, as well as the specificity that they have with certain hosts, under the controlled laboratory conditions.

Here, we investigated the effects of different $\mathrm{pH}$ levels, salt stress and drought stress on mycelial growth of ECM fungus Xerocomus badius (synonyms for Boletus badius and Imleria badia) (Species Fungorum 2019) in the tolerance test. Based on the findings from the tolerance test with $X$. badius and the verified mutualistic symbiosis between Lolium multiflorum Lam. and $X$. badius driven by seed inoculation (Liu et al. 2019), we propose that $X$. badius is expected to enhance stress tolerance of L. multiflorum Lam. under drought and salt stresses. Therefore, symbiotic tests were carried out to investigate the effect of seed-priming with the spore suspensions of $X$. badius on seed germination and seedling growth of $L$. multiflorum Lam. under different $\mathrm{NaCl}$-induced salt stress and PEG-induced drought stress conditions.

The general, objective of this study was (1) to evaluate the stress tolerance of $X$. badius under different $\mathrm{pH}$ values, salt concentrations and drought, that could be helpful in determining optimized protocols for the vegetative propagation under laboratory conditions, and to (2) verify the improvement effect of seed priming with fungus suspension on seed germination and seedling growth of L. multiflorum Lam. under drought and salt stressed conditions, that could have important implications for the use of these fungi as inoculants on agricultural crops.

\section{Materials and methods}

\section{Plant material, fungus strain and inoculum preparation}

Seeds of $L$. multiflorum Lam. and ECM fungus $X$. badius (Preservation No. cfcc5946) were obtained from the Xinrui Seed Industry Limited Company and China Forestry Culture Collection Center, respectively. Fungus maintenance, incubation, inoculation, and seeds pretreatment followed the methods of Liu et al.. (Liu et al. 2019).

\section{Effect of $\mathrm{pH}$, salt, and drought stress on mycelial growth} of $X$. badius

Three single-factor ( $\mathrm{pH}$, salt, or drought) experiments were performed. Five $\mathrm{pH}$ values, namely, 5.00, 6.00, 7.00, 8.00 , and 9.00 , were implemented to study the effect of $\mathrm{pH}$ on the mycelial growth of $X$. badius. Prior to sterilization, the $\mathrm{pH}$ level of the potato dextrose agar (PDA) medium was adjusted with an electronic $\mathrm{pH}$ meter (PHS-3C, INESA Ltd, Shanghai, China) by adding $\mathrm{HCl}$ $\left(1.00 \mathrm{~mol} \mathrm{~L}^{-1}\right)$ or $\mathrm{KOH}\left(1.00 \mathrm{~mol} \mathrm{~L}^{-1}\right)$. Salt stress was imposed by adding $0.20 \%(\mathrm{w} / \mathrm{v}), 0.40 \%(\mathrm{w} / \mathrm{v}), 0.60 \%$ $(\mathrm{w} / \mathrm{v})$, and $0.80 \%(\mathrm{w} / \mathrm{v}) \mathrm{NaCl}$ (corresponding to 34.22 , $68.45,102.67$ and $136.89 \mathrm{mmol} \mathrm{L}^{-1}$ ) to the PDA medium $(\mathrm{pH}=6.50)$ before sterilization. $X$. badius growing at the absence of $\mathrm{NaCl}$ was used as the control. Drought stress was induced using $0.00 \%(\mathrm{w} / \mathrm{v}), 5.00 \%(\mathrm{w} / \mathrm{v}), 10.00 \%$ $(\mathrm{w} / \mathrm{v}), 15.00 \%(\mathrm{w} / \mathrm{v})$, and $20.00 \%(\mathrm{w} / \mathrm{v})$ polyethylene glycol with a molecular weight of 6000 (PEG-6000) to adjust the water potential of the PDA medium $(\mathrm{pH}=6.50)$ to approximately $-0.16,-0.27,-0.45,-0.72$, and $-1.07 \mathrm{MPa}$, respectively. As PEG reduces agar solidification, fungal isolates were grown in liquid medium (potato dextrose medium). To avoid submersion, a sterilized grit support was placed in the Petri dish with the liquid medium just covering the grit, and a fiber filter was placed on the grit with an inoculation on the filter.

All colonies were cultured in Petri dishes (diameter: $9.00 \mathrm{~cm}$ ) filled with $10.00 \mathrm{~mL}$ of the modified culture medium as described above. Mycelial plugs with diameter of $5.00 \mathrm{~mm}$ were taken from the 7-day-old colony edge by using a sterilized mechanical puncher and transferred to the different tested media. At least six replicates were performed for each treatment. The inoculated Petri dishes were sealed with a strip of parafilm and maintained in the dark at $25.00 \pm 1.00{ }^{\circ} \mathrm{C}$ and $60.00 \%$ relative humidity for 10 days in an incubator with constant humidity.

\section{Effect of $X$. badius inoculation on seed germination and seedling growth of $L$. multiflorum Lam. under salt and drought conditions}

For each treatment, $30 \mathrm{X}$. badius-inoculated or non-inoculated seeds of $L$. multiflorum Lam. were sown in each Petri dish (diameter: $9.00 \mathrm{~cm}$ ) with two layers of humid filter paper covered at the bottom. Two days after sowing, salt and drought were applied to the $X$. badius-inoculated and non-inoculated seeds. Salt stress was applied by adding $0.00 \%(\mathrm{w} / \mathrm{v}), 0.40 \%(\mathrm{w} / \mathrm{v})$, and $0.80 \%(\mathrm{w} / \mathrm{v}) \mathrm{NaCl}$ (according to the preliminary experiment) in the sterilized deionized water. Drought was imposed by adding $0.00 \%(\mathrm{w} / \mathrm{v}), 10.00 \%(\mathrm{w} / \mathrm{v})$, and $20.00 \%(\mathrm{w} / \mathrm{v})$ PEG-6000 in the sterilized deionized water. All Petri dishes were 
placed in a random position on a shelf in the laboratory. The experiment lasted for 2 weeks, during which all seedlings were watered every other day with $\mathrm{NaCl}$, PEG-6000 solution, or sterilized water (control) and supplied twice a week with sterilized half-strength Hoagland's solution $(\mathrm{pH}=6.50)$ (Hoagland and Arnon 1950). In the meantime, the residual solution was poured out, and the filter papers were changed to avoid the effects of ion accumulation. To avoid edge effects, all Petri dishes were rotated weekly.

\section{Measurements of colony diameter (CD) and colony average} growth rate (CGR)

After 7 days of incubation, the CD in different media was measured in the perpendicular direction using a beveled straightedge. The average of two diameter measurements along the perpendicular axes was used to estimate the colony size during the incubation period. The CGR was determined as the average increase in diameter divided by the total number of incubation days.

\section{Measurements of seed germination rate (GR), shoot height (SH), and seedling total fresh weight (FW)}

One week after sowing, the cumulative number of germinated seeds in the different treatments was recorded, and the GR, which was defined as one hundred times the number of germinated seeds divided by the total number of seeds, was calculated. At the end of the experiment, the seedlings in the different treatments were harvested separately, washed in running tap water to remove the chemical substances, and divided into shoot and root portions. The SH and FW were measured.

\section{Statistical analyses}

The experiments were performed using a completely randomized design. All the measurements were conducted in sextuplicate at least. Data were presented as mean \pm standard deviation. Statistical analysis was carried out using the SPSS-13.0 for Windows (Standard released version 13.0 for Windows; SPSS Inc., IL, USA). One-way analysis of variance (ANOVA) was used to evaluate the effects of different $\mathrm{pH}$ values, salt concentrations and drought on mycelial growth of $X$. badius. Two-way ANOVA was used to evaluate the effects of $X$. badius inoculation and salt or drought stress on seed germination and seedling growth of L. multiflorum Lam.. Tukey's honestly significant difference (HSD) post hoc test $(P \leq 0.05)$ was performed to test the existence of statistical differences for the same parameter among different treatments.

\section{Results}

Effect of $\mathrm{pH}$ on mycelial growth

One-way ANOVA showed that the $\mathrm{pH}$ level of the medium had no significant influence on the mycelial growth of $X$. badius $(P>0.05$, Table 1$)$. $X$. badius mycelium had the ability to grow well at a wide $\mathrm{pH}$ range of $5.00 \sim 9.00$. After 7 days of incubation, $X$. badius cultured in the medium with $\mathrm{pH} 8.00$ showed the largest $\mathrm{CD}$ $(7.14 \mathrm{~cm})$ and the highest CGR $\left(1.43 \mathrm{~cm} \mathrm{day}^{-1}\right)$, and the smallest CD $(6.83 \mathrm{~cm})$ and lowest CGR $\left(1.37 \mathrm{~cm}\right.$ day $\left.^{-1}\right)$ were observed in medium with $\mathrm{pH} 5.00$. However, statistical analysis showed no significant difference $(P>0.05)$ in the CD and CGR among the media with different $\mathrm{pH}$ levels.

\section{Effect of salt stress on mycelial growth}

The $\mathrm{NaCl}$ concentration of the culture medium had significant negative effect on the mycelial growth of $X$. badius $(P<0.001$, Table 2$)$. Significant differences in the $C D$ and CGR of $X$. badius were observed among the media with different $\mathrm{NaCl}$ concentrations $(P \leq 0.05$, Table 2). $X$. badius in the control medium (without $\mathrm{NaCl}$ ) grew best, as manifested by the largest $\mathrm{CD}(7.56 \mathrm{~cm})$ and highest CGR $\left(1.51 \mathrm{~cm} \mathrm{day}^{-1}\right)$. By contrast, the mycelial growth of $X$. badius in the presence of $\mathrm{NaCl}$ was significantly inhibited and decreased with increasing $\mathrm{NaCl}$ concentration. $X$. badius in $0.80 \% \mathrm{NaCl}$ medium showed the smallest CD $(5.83 \mathrm{~cm})$ and lowest CGR $\left(1.17 \mathrm{~cm} \mathrm{day}^{-1}\right)$.

\section{Effect of drought stress on mycelial growth}

PEG-induced drought stress had significant effect on the mycelial growth of $X$. badius $(P<0.001$, Table 3$)$. The $\mathrm{CD}$ and CGR of $X$. badius in the control $(-0.16 \mathrm{MPa})$ were $8.27 \mathrm{~cm}$ and $1.18 \mathrm{~cm} \mathrm{day}^{-1}$, respectively. The CD $(8.18 \mathrm{~cm})$ and CGR $\left(1.17 \mathrm{~cm} \mathrm{day}^{-1}\right)$ of $X$. badius in $5.00 \%$ PEG $(-0.27 \mathrm{MPa})$ medium were not significantly different $(P>0.05)$ from those of the control. By

Table 1 Influence of the medium pH on mycelial growth of $X$. badius

\begin{tabular}{llll}
\hline pH & Colony diameter $(\mathbf{c m})$ & $\begin{array}{l}\text { Colony average } \\
\text { growth rate }(\mathbf{c m} \\
\left.\text { day }^{-1}\right)\end{array}$ & One-way ANOVA \\
\hline 5.00 & $6.83 \pm 0.25 a$ & $1.37 \pm 0.05 a$ & 0.988 \\
6.00 & $6.91 \pm 0.35 a$ & $1.38 \pm 0.07 a$ & \\
7.00 & $7.00 \pm 0.29 a$ & $1.40 \pm 0.06 a$ & \\
8.00 & $7.14 \pm 0.31 a$ & $1.43 \pm 0.06 a$ & \\
9.00 & $6.89 \pm 0.32 a$ & $1.38 \pm 0.06 a$ & \\
\hline
\end{tabular}

Data are presented as mean of at least six replicates \pm standard deviation. Small letters in the same column show statistically significant differences among different $\mathrm{pH}$ treatments for the same parameter at $P \leq 0.05$ based on Tukey's HSD post hoc test 
contrast, the mycelial growth of $X$. badius was significantly inhibited by $10.00 \sim 20.00 \%$ PEG-induced drought stress $(-0.45 \sim-1.07 \mathrm{MPa})$. Incubation in $20.00 \%$ PEG $(-1.07 \mathrm{MPa})$ medium produced the smallest $\mathrm{CD}$ $(2.28 \mathrm{~cm})$ and lowest CGR $\left(0.33 \mathrm{~cm} \mathrm{day}^{-1}\right)$.

Effect of $X$. badius inoculation on seed germination of $L$. multiflorum Lam. under salt and drought conditions

$X$. badius inoculation $(P \leq 0.001)$, salinity $(P \leq 0.001)$ and their interaction $(P \leq 0.05)$ had significant effects on the GR (Table 4). In comparison with the non-saline treatment, the GRs of both non-inoculated and $X$. badius-inoculated L. multiflorum Lam. seeds were decreased by the $\mathrm{NaCl}$-induced salt stress, and the non-inoculated seeds showed larger decrease in GR than the $X$. badius-inoculated ones. Compared with the nonsaline condition, $0.40 \%$ and $0.80 \% \mathrm{NaCl}$ induced $17.99 \%$ and $43.47 \%$ decrease in the GR of the non-inoculated seeds, respectively. The GRs of the $X$. badius-inoculated seeds decreased by 5.49 and $28.84 \%$ under $0.40 \%$ and $0.80 \% \mathrm{NaCl}$ condition, respectively. Under non-saline condition, $X$. badius had no significant influence on the

Table 2 Influence of $\mathrm{NaCl}$-induced salt stress on mycelial growth of $X$. badius

\begin{tabular}{llll}
\hline NaCl concentration $(\%)$ & Colony diameter $(\mathbf{c m})$ & Colony average growth rate $\left(\mathbf{c m}\right.$ day $\left.{ }^{-\mathbf{1}}\right)$ & One-way ANOVA $^{-}$ \\
\hline 0.00 & $7.56 \pm 0.21 \mathrm{a}$ & $1.51 \pm 0.04 \mathrm{a}$ & $45.669^{* * *}$ \\
0.20 & $7.16 \pm 0.26 \mathrm{~b}$ & $1.43 \pm 0.05 \mathrm{~b}$ & \\
0.40 & $6.68 \pm 0.37 \mathrm{c}$ & $1.34 \pm 0.07 \mathrm{c}$ \\
0.60 & $6.53 \pm 0.28 \mathrm{c}$ & $1.31 \pm 0.06 \mathrm{c}$ \\
0.80 & $5.83 \pm 0.17 \mathrm{~d}$ & $1.17 \pm 0.03 \mathrm{~d}$
\end{tabular}

Data are presented as mean of at least six replicates \pm standard deviation. Small letters in the same column show statistically significant differences among different $\mathrm{NaCl}$-induced salt stress treatments for the same parameter at $P \leq 0.05$ based on Tukey's HSD post hoc test. ${ }^{* * *}$ Significant at $P \leq 0.001$

Table 3 Influence of PEG-6000-induced drought stress on mycelial growth of $X$. badius

\begin{tabular}{llll}
\hline PEG-6000 concentration (\%) & Colony diameter $(\mathbf{c m})$ & Colony average growth rate $\left(\mathbf{c m}\right.$ day $\left.{ }^{-\mathbf{1}}\right)$ & One-way ANOVA $^{-}$ \\
\hline 0.00 & $8.27 \pm 0.16 \mathrm{a}$ & $1.18 \pm 0.04 \mathrm{a}$ & $96.365^{* * *}$ \\
5.00 & $8.18 \pm 0.09 \mathrm{a}$ & $1.17 \pm 0.05 \mathrm{a}$ & \\
10.00 & $6.83 \pm 0.12 \mathrm{~b}$ & $0.98 \pm 0.07 \mathrm{~b}$ \\
15.00 & $5.89 \pm 0.23 \mathrm{c}$ & $0.84 \pm 0.06 \mathrm{c}$ \\
20.00 & $2.28 \pm 0.43 \mathrm{~d}$ & $0.33 \pm 0.03 \mathrm{~d}$ \\
\hline
\end{tabular}

Data are presented as mean of at least six replicates \pm standard deviation. Small letters in the same column show statistically significant differences among different PEG-induced drought stress treatments for the same parameter at $P \leq 0.05$ based on Tukey's HSD post hoc test. ***Significant at $P \leq 0.001$

Table 4 Effect of $X$. badius inoculation on seed germination and seedling growth of $L$. multiflorum Lam. under different $\mathrm{NaCl}$-induced salt conditions

\begin{tabular}{|c|c|c|c|c|}
\hline & $\mathrm{NaCl}$ concentration (\%) & Germination rate (\%) & Shoot height $(\mathrm{cm})$ & $\begin{array}{l}\text { Seedling } \\
\text { fresh weight } \\
\text { (g) }\end{array}$ \\
\hline \multirow[t]{3}{*}{ Non-inoculated } & 0.00 & $93.29 \pm 2.01 a$ & $22.61 \pm 1.01 a$ & $5.64 \pm 0.55 b$ \\
\hline & 0.40 & $76.51 \pm 1.74 b$ & $18.33 \pm 1.54 b c$ & $4.76 \pm 0.62 c$ \\
\hline & 0.80 & $52.74 \pm 4.63 d$ & $14.67 \pm 1.63 d$ & $3.22 \pm 0.43 d$ \\
\hline \multirow[t]{3}{*}{ X. badius-inoculated } & 0.00 & $90.67 \pm 1.89 a$ & $26.14 \pm 1.29 a$ & $7.20 \pm 0.18 a$ \\
\hline & 0.40 & $85.69 \pm 3.22 \mathrm{ab}$ & $23.29 \pm 1.22 \mathrm{a}$ & $6.05 \pm 0.39 b$ \\
\hline & 0.80 & $64.52 \pm 2.98 c$ & $18.83 \pm 1.98 \mathrm{bc}$ & $4.27 \pm 0.47 c$ \\
\hline \multicolumn{5}{|l|}{ Two-way ANOVA } \\
\hline Salt & & $34.710^{* * *}$ & $6.408^{* *}$ & $383.828^{* * *}$ \\
\hline X.badius & & $18.866^{* * *}$ & $142.712^{* * *}$ & $372.925^{* * *}$ \\
\hline Salt $\times X$. badius & & $3.272^{*}$ & $9.544^{* * *}$ & $10.846^{* * *}$ \\
\hline
\end{tabular}

Data are presented as mean of six replicates \pm standard deviation. Small letters in the same column show statistically significant differences among different salt stress treatments for the same parameter at $P \leq 0.05$ based on Tukey's HSD post hoc test. ${ }^{*},{ }^{* *}$ and ${ }^{* * *}$ Significant at $P \leq 0.05,0.01$, and 0.001, respectively 
GR of L. multiflorum Lam., but the GR was enhanced by $X$. badius under $0.40 \%$ and $0.80 \% \mathrm{NaCl}$-induced saline conditions. Compared with the non-inoculated seeds, the GRs of the $X$. badius-inoculated seeds increased by $12.00 \%$ and $22.34 \%$ under $0.40 \%$ and $0.80 \% \mathrm{NaCl}$ condition, respectively.

Compared with the non-drought condition, the PEG-induced drought decreased the GRs of both noninoculated and $X$. badius-inoculated seeds, and the noninoculated seeds showed larger decrease in GR than the $X$. badius-inoculated ones (Table 5). Compared with the non-drought condition, $10.00 \%$ PEG-induced drought stress led to $24.31 \%$ and $9.23 \%$ decrease in the GRs of the non-inoculated and $X$. badius-inoculated seeds, respectively. Meanwhile, 20.00\% PEG-induced drought stress led to $49.32 \%$ and $37.20 \%$ decrease in the GRs of the non-inoculated and $X$. badius-inoculated seeds, respectively. Under non-drought condition, $X$. badius had no significant influence on the GR of L. multiflorum Lam., but $X$. badius enhanced GR of L. multiflorum Lam. under $10.00 \%$ and $20.00 \%$ PEG-induced drought conditions. Compared with the non-inoculated seeds, the GRs of the $X$. badius-inoculated seeds increased by $19.51 \%$ and $23.48 \%$ under $10.00 \%$ and $20.00 \%$ PEG condition, respectively.

Effect of $X$. badius inoculation on seedling growth of $L$. multiflorum Lam. under salt and drought conditions $X$. badius inoculation, salinity, and their interaction had significant effects on the SH and FW (Table 4). Compared with those under the non-saline condition, salt stress inhibited the growth and biomass accumulation of non-inoculated and X. badius-inoculated L. multiflorum Lam. seedlings, and the non-inoculated seedlings showed a larger decrease than the $X$. badius-inoculated ones (Fig. 1). Compared with those under the non-saline condition, under $0.40 \% \mathrm{NaCl}$ condition, the SHs of the noninoculated and $X$. badius-inoculated seedlings decreased

Table 5 Effect of $X$. badius inoculation on seed germination and seedling growth of $L$. multiflorum Lam. under different PEG-6000-induced drought conditions

\begin{tabular}{|c|c|c|c|c|}
\hline & $\begin{array}{l}\text { PEG-6000 concentration } \\
(\%)\end{array}$ & Germination rate (\%) & Shoot height $(\mathrm{cm})$ & $\begin{array}{l}\text { Seedling } \\
\text { fresh weight } \\
\text { (g) }\end{array}$ \\
\hline \multirow[t]{3}{*}{ Non-inoculated } & 0.00 & $92.18 \pm 1.88 \mathrm{a}$ & $23.22 \pm 1.72 b$ & $5.58 \pm 0.38 b$ \\
\hline & 10.00 & $69.77 \pm 1.89 b c$ & $16.45 \pm 1.36 \mathrm{~cd}$ & $3.92 \pm 0.39 c$ \\
\hline & 20.00 & $46.72 \pm 3.18 d$ & $13.86 \pm 1.29 \mathrm{~d}$ & $2.74 \pm 0.51 d$ \\
\hline \multirow[t]{3}{*}{ X. badius-inoculated } & 0.00 & $91.86 \pm 3.21 a$ & $27.76 \pm 2.01 a$ & $7.19 \pm 0.25 a$ \\
\hline & 10.00 & $83.38 \pm 2.77 a b$ & $21.39 \pm 1.17 b$ & $5.36 \pm 0.44 b$ \\
\hline & 20.00 & $57.69 \pm 3.26 c$ & $17.90 \pm 1.43 c$ & $3.88 \pm 0.71 c$ \\
\hline \multicolumn{5}{|l|}{ Two-way ANOVA } \\
\hline Drought & & $41.099^{* * *}$ & $53.134^{* * *}$ & $121.025^{* * *}$ \\
\hline$X$. badius & & $12.247^{* * *}$ & $76.028^{* * *}$ & $115.298^{* * *}$ \\
\hline Drought $\times X$. badius & & $7.418^{* *}$ & $13.532^{* * *}$ & $4.952^{*}$ \\
\hline
\end{tabular}

Data are presented as mean of six replicates \pm standard deviation. Small letters in the same column show statistically significant differences among different drought stress treatments for the same parameter at $P \leq 0.05$ based on Tukey's HSD post hoc test. ${ }^{*}{ }^{* *}$ and ${ }^{* * *}$ Significant at $P \leq 0.05,0.01$, and 0.001 , respectively

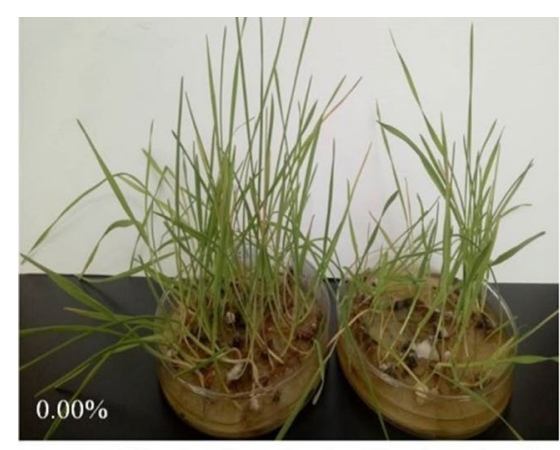

X. badius-inoculated Non-inoculated

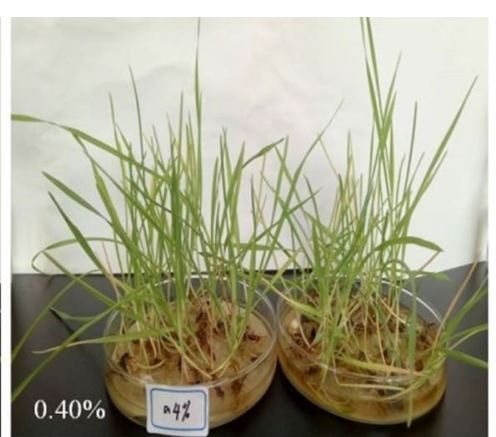

$X$. badius-inoculated Non-inoculated

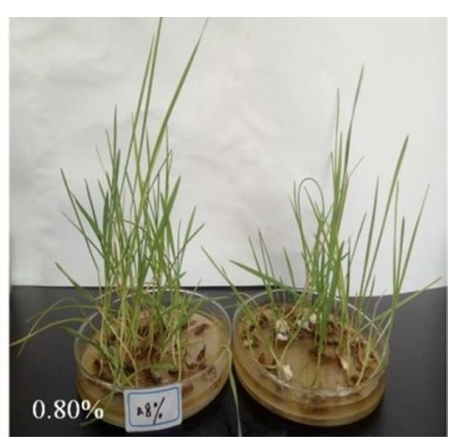

X. badius-inoculated Non-inoculated

Fig. 1 Typical phenotype of L. multiflorum Lam. seedlings 2 weeks after inoculation or non-inoculation with X. badius under different NaCl-induced salt conditions 
by $18.93 \%$ and $15.60 \%$, respectively, while the FWs decreased by $10.90 \%$ and $15.97 \%$, respectively. Under $0.80 \% \mathrm{NaCl}$ condition, the SHs of the non-inoculated and $X$. badius-inoculated seedlings decreased by $35.12 \%$ and $42.91 \%$ respectively, while the FWs decreased by $27.96 \%$ and $40.69 \%$, respectively. $X$. badius inoculation improved the SH and FW of L. multiflorum Lam. seedlings under non-saline and saline conditions. Under non-saline condition, $X$. badius increased the SH and FW by $15.61 \%$ and $27.66 \%$, respectively. Under $0.40 \%$ and $0.80 \% \mathrm{NaCl}$ condition, $X$. badius increased $\mathrm{SH}$ by $27.06 \%$ and $28.36 \%$, respectively, while the FWs of the $X$. badius-inoculated seedlings increased by $27.10 \%$ and $32.61 \%$, respectively.

$X$. badius inoculation, drought, and their interaction had significant effects on the SH and FW (Table 5). Compared with those under the non-drought condition, drought stress inhibited the growth and biomass accumulation of non-inoculated and $X$. badius-inoculated L. multiflorum Lam. seedlings, and the non-inoculated seedlings showed a larger decrease than the $X$. badiusinoculated ones (Fig. 2). Compared with those under the non-drought condition, the SHs of the non-inoculated and $X$. badius-inoculated seedlings decreased by $29.16 \%$ and $22.95 \%$, respectively, under $10.00 \%$ PEG condition and by $40.31 \%$ and $37.36 \%$, respectively, under $20.00 \%$ PEG condition. The FWs of the non-inoculated and $X$. badius-inoculated seedlings decreased by $29.75 \%$ and $25.45 \%$, respectively, under $10.00 \%$ PEG condition and by $50.90 \%$ and $46.04 \%$, respectively, under $20.00 \%$ PEG condition. $X$. badius inoculation improved the SHs and FWs of the L. multiflorum Lam. seedlings under non-drought and drought stress conditions. Compared with those of the non-inoculated seedlings, the SHs of the $X$. badiusinoculated seedlings increased by $19.55 \%, 30.03 \%$, and $29.15 \%$ under $0.00 \%, 10.0 \%$, and $20.00 \%$ PEG-induced drought condition, respectively, and the FWs increased by $28.86 \%, 36.73 \%$, and $41.61 \%$ under $0.00 \%, 10.00 \%$, and 20.00\% PEG-induced drought condition, respectively.

\section{Discussion}

\section{Effect of $\mathrm{pH}$ on mycelial growth}

The $\mathrm{pH}$ level is one of the crucial factors affecting the mycorrhizal fungus growth and development mainly by influencing the nutrient availability of the culture medium (Daza et al. 2006; Lazarević et al. 2016; Xu et al. 2008). ECM fungi can grow under conditions from acidic to slight alkaline (Zhu et al. 2008; Siri-in et al. 2014), but each fungal species has its optimum $\mathrm{pH}$ level for mycelial growth (Lazarević et al. 2016). For example, the mycelium of Scleroderma sinnamariense can grow at a $\mathrm{pH}$ range of $2.00 \sim 9.00$, with the optimal pH of 5.00 (Siri-in et al. 2014). Boletus edulis and Hebeloma sp. showed the largest $\mathrm{CD}$ at $\mathrm{pH} 5.00$, and Laccaria bicolor and Laccaria deliciosus grew best at $\mathrm{pH} 6.00$ (Xu et al. 2008). The optimum $\mathrm{pH}$ levels of the aforementioned fungi were lower than 6.00, suggesting a good adaption to acid conditions. However, fungal species, such as Amanita caesarea (Daza et al. 2006), Laccaria insulsus (Xu et al. 2008), and some pleosporalean fungi from saline areas (Qin et al. 2017), grow best at neutral or slightly alkaline conditions. $X$. badius was isolated from soils with a $\mathrm{pH}$ range of $6.50 \sim 7.50$. The colony may grow well in a culture medium with a $\mathrm{pH}$ level similar to its natural soil environments. Therefore, the $\mathrm{pH}$ conditions of the soil from which the fungi are isolated should be considered to optimize the culture and propagation of the fungi in the laboratory and to improve the production of mycorrhizal plants in the nursery. The results indicated that the mycelium of $X$. badius could grow well at the wide $\mathrm{pH}$ range of $5.00 \sim 9.00$ (Table 1). After 7 days of incubation, $X$. badius grown at $\mathrm{pH} 8.00$ showed the largest $\mathrm{CD}$ and the highest CGR, and the smallest CD and the lowest CGR were observed at $\mathrm{pH}$ 5.00. However, no significant difference $(P>0.05)$ were found in the CDs and CGRs among the media with different $\mathrm{pH}$ values (Table 1 ). $X$. badius might present high resistance under alkaline conditions, and

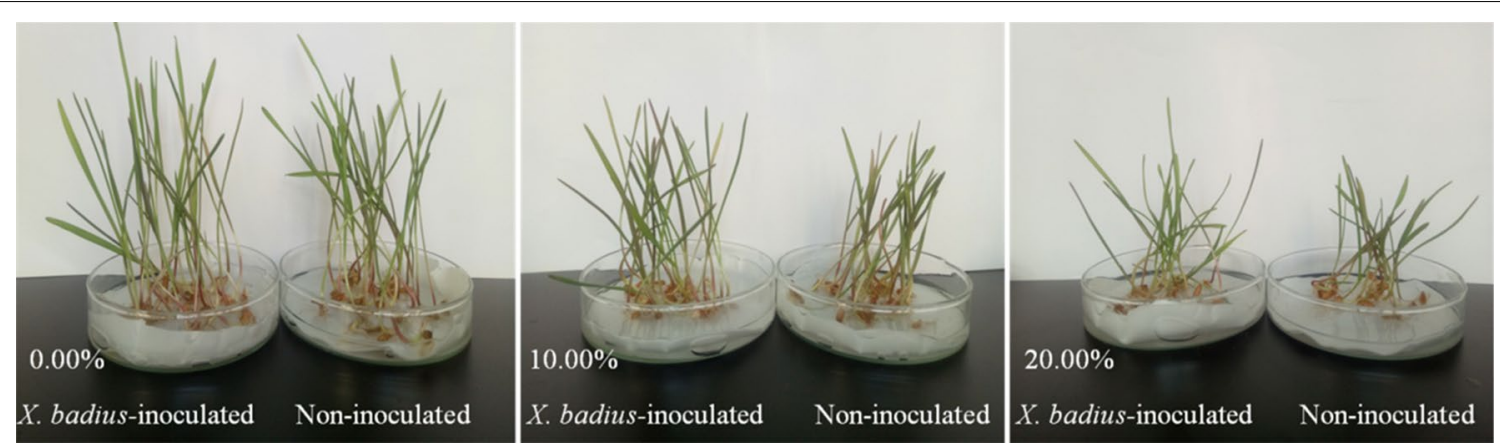

Fig. 2 Typical phenotype of L. multiflorum Lam. seedlings 2 weeks after inoculation or non-inoculation with X. badius under different PEG-6000-induced drought conditions 
this characteristic is typical of alkalophilic fungal species (Kulkarni et al. 2019).

\section{Effect of salt stress on mycelial growth}

Salt stress is one of the most important limiting factors in agriculture worldwide. The practical use of beneficial mycorrhizal fungi with high salt tolerance has been proved to be one of the most effective strategies to alleviate the adverse effects on crops in saline areas (GuerreroGalán et al. 2019; Kumar and Verma 2018). Salt-tolerance evaluation of mycorrhizal fungi in the laboratory could provide a useful theoretical reference for the selection of the proper fungal strain. In this study, $X$. badius was very sensitive to salt stress, although the mycelium also grew very well, that is consistent with observations on other fungi (Qin et al. 2017; Tang et al. 2009). Mycelial growth, as reflected by CD and CGR, was significantly inhibited with increasing $\mathrm{NaCl}$ concentration $(P<0.001$, Table 2$)$. $X$. badius in the non-saline medium grew best as manifested by the highest value in CD and CGR. X. badius in $0.80 \% \mathrm{NaCl}$ medium showed the lowest value in $\mathrm{CD}$ and CGR, suggesting the worst growth performance (Table 2). Probably, X. badius had poor ability to absorb $\mathrm{Na}^{+}$and $\mathrm{Cl}^{-}$, and the accumulation of these redundant ions in the medium resulted in low water potential and then reduced the availability of nutrient and water for the fungi (Kumar and Verma 2018), thereby leading to the restriction of mycelial growth. Despite its salt sensitivity, $X$. badius could still grow and survive in $0.80 \% \mathrm{NaCl}$ medium, suggesting that this species is more likely halotolerant but not halophilic.

However, in nature, soil salinity is caused not only by $\mathrm{NaCl}$ but also by magnesium, calcium, potassium, etc. (Chen et al. 2019). More future researches focused on the effect of natural soil salinity on the growth of mycelia and the host plant should be carried out, that have more realistic significance in the utilization of salinity soil.

\section{Effect of drought stress on mycelial growth}

Researches on the effect of PEG-induced drought stress on mycelial growth have been carried out with many ECM fungal strains (Navarro-Ródenas et al. 2011; Zhang et al. 2011; Zhu et al. 2008). In this study, the growth response of $X$. badius to drought stress induced by PEG-6000 was assessed. The results showed that 5.00\% PEG-induced drought stress had no significant negative influence on the CD and CGR of $X$. badius $(P>0.05$, Table 3). However, the mycelial growth of $X$. badius was significantly inhibited under $10.00 \% \sim 20.00 \%$ PEGinduced drought conditions as manifested by the significant decrease in CD and CGR $(P \leq 0.05$, Table 3$)$. Mycelial growth under water-controlled conditions could reflect the adaptability of fungus to dry soil and the ability of the fungus to enhance the drought resistance of its host plants (Duñabeitia et al. 2004). Also, host plants may influence the morphology and physiology of the fungus after mycorrhization (Zhang et al. 2011). Therefore, it is necessary to establish fungus-mycorrhiza-host plant symbiont and study the associating drought resistance prior to practical application.

\section{Effect of seed priming with $X$. badius suspensions on seed germination and seedling growth of $L$. multiflorum Lam. under salt and drought conditions}

Drought and high salinity are the two most important environmental factors that adversely affect the seed germination of crops and the survival, growth, and productivity of plants. In recent years, seed biopriming with PGPF spore suspensions has been extensively proved to be beneficial for the seed germination and seedling growth of crops under non-stress and stress conditions (Bonfante and Genre 2010; de Zelicourt et al. 2013; Guerrero-Galán et al. 2019; Hossain et al. 2017; Javeria et al. 2017; Kumar and Verma 2018; Tomer et al. 2016; Vijayabharathi et al. 2016; Vimal et al. 2017; Yan et al. 2019). Based on the findings from the tolerance test of $X$. badius and the verified mutualistic symbiosis between L. multiflorum Lam. and $X$. badius driven by seed inoculation (Liu et al. 2019), the effect of seed priming with spore suspensions of $X$. badius on seed germination and seedling growth of L. multiflorum Lam. were investigated under different salt and drought conditions. The results indicated that seed priming with $X$. badius had no significant effect on the GR under non-stress condition $(P>0.05$, Tables 4 and 5 ), that is consistent with our previous study (Liu et al. 2019) and studies on bromeliad (Leroy et al. 2019), barley and oat (Murphy et al. 2017) inoculated by other PGPF species. However, GR was significantly enhanced by seed priming with $X$. badius under drought and salt stress conditions. $X$. badius inoculation greatly improved the $\mathrm{SH}$ and $\mathrm{FW}$ of L. multiflorum Lam. seedlings under non-stress and drought/ salt stress conditions (Figs. 1 and 2). The improvement under stress conditions was markedly higher than that under non-stress conditions ( $P \leq 0.05$, Tables 4 and 5$)$. Similar improvements in seed germination and seedling growth induced by mycorrhizal fungi inoculation with seeds have also been reported on Dendrobium officinale (Tan et al. 2014) and other epiphytic orchid species (Alghamdi 2019). The results also showed that $X$. badius inoculation led to earlier seed germination and greater survival of seedlings compared with the non-inoculated seeds under non-stress and stress conditions. Thus, fungal inoculation with seeds was not very essential for seed germination under non-stress 
and mild stress conditions but contributed highly to the survival and growth of the seedlings especially under severe stress conditions. The symbiotically associated fungi could promote the degradation of the cuticle cellulose of the seed resulting in the alleviated restriction of seed coat and then earlier germination. In addition, it can also produce many plant growth-promoting compounds such as phytohormones (gibberellins and indole acetic acid) and secondary metabolites, and enhance water and nutrient availability, which are conducive to seed germination and subsequent seedling growth (Behie and Bidochka 2014; Cairney 2012; Garcia et al. 2016; Hossain et al. 2017; Javeria et al. 2017; Owen et al. 2015; Shen et al. 2018).

In comparison with the non-stress condition, $\mathrm{NaCl}-$ induced salt stress and PEG-induced drought stress decreased GR, SH, and FW of the non-inoculated and $X$. badius-inoculated seeds/seedlings, and the noninoculated seeds/seedlings showed larger decrease in these three parameters than the $X$. badius-inoculated ones (Figs. 1 and 2; Tables 4 and 5). The GRs, SHs, and FWs of both non-inoculated and X. badius-inoculated L. multiflorum Lam. seeds/seedlings decreased rapidly with the increase of $\mathrm{NaCl}$ and PEG concentrations, and PEG showed more negative effect than that of $\mathrm{NaCl}$ (Tables 4 and 5), which is in agreement with the results from previous studies (Murillo-Amador et al. 2002; Petrović et al. 2016). The inhibition by salt and drought stress on seed germination was mainly due to the limited water uptake by the seed, which caused the subsequent inhibition on the seedling growth. Probably, the accumulation of $\mathrm{Na}^{+}$and $\mathrm{Cl}^{-}$in the substrate could also result in the toxic effect on seed germination and seedling growth by creating an external osmotic potential (Zhang et al. 2010). Compared with that under the PEG solution, the osmotic potential difference caused by the ion accumulation in the $\mathrm{NaCl}$ solution can also induce the rapid water uptake of seed and thereby enough water content for earlier seed germination.

In conclusion, the experimental evidence of the ability of $X$. badius to adapt to a series of environmental stresses, including $\mathrm{pH}$, salt stress, and drought stress, is presented. The results indicated that $X$. badius had a wide $\mathrm{pH}$ tolerance, especially high alkali tolerance, and might has good adaptation to alkali environments. Furthermore, seed priming with spore suspensions of $X$. badius was not essential to the seed germination of L. multiflorum Lam. under non-stress and mild stress conditions, but induced a beneficial effect on the subsequent seedling growth under severe salt and drought stress conditions. Hence, the successful establishment of $X$. badius on $L$. multiflorum Lam. seedlings under stressful conditions can be an effective approach to increase the plant tolerance to withstand environmental stresses.

\begin{abstract}
Acknowledgements
The authors acknowledge financial support from the National Natural Science Foundation of China, the Forestry Science and Technology Innovation Project of Shandong Province and the Key Research and Development Program of Shandong Province. The authors are grateful to Yang Li for help in revising our English composition.
\end{abstract}

\section{Authors' contributions}

$B L, F L$ and $H M$ designed the study. BL, XL and LP performed research. BM contributed method of PEG-induced drought stress treatment. The first draft of the manuscript was written by BL and all authors commented on previous versions of the manuscript. All authors read and approved the final manuscript.

\section{Funding}

This work was supported by the National Natural Science Foundation of China (Grant No. 31570614), the Forestry Science and Technology Innovation Project of Shandong Province (2019LY009) and the Key Research and Development Program of Shandong Province (2019GNC106081).

\section{Availability of data and materials}

The authors declare that all the data and materials used in this study are available.

\section{Ethics approval and consent to participate}

This article does not contain any studies with human participants or animals performed by any of the authors.

\section{Consent for publication}

All authors agree with the contents of the manuscript and its submission to the journal.

\section{Competing interests}

The authors declare that they have no competing interests.

\section{Author details}

1 Shandong Academy of Forestry, 42, East Wenhua Road, Shandong 250014 Jinan, China. ${ }^{2}$ Economic Forest Products Quality Inspection Test Center of State Forestry Administration (Jinan), Shandong 250014 Jinan, China. ${ }^{3}$ Shandong Engineering Research Center for Ecological Restoration of Forest Vegetation, Shandong 250014 Jinan, China.

Received: 23 August 2020 Accepted: 24 December 2020

Published online: 07 January 2021

\section{References}

Alghamdi SA (2019) Influence of mycorrhizal fungi on seed germination and growth in terrestrial and epiphytic orchids. Saudi J Biol Sci 26:495-502. https://doi.org/10.1016/j.sjbs.2017.10.021

Becquer A, Guerrero-Galán C, Eibensteiner JL, Houdinet G, Bücking H, Zimmermann SD, Garcia K (2019) The ectomycorrhizal contribution to tree nutrition. Adv Bot Res 89:77-126. https://doi.org/10.1016/bs.abr.2018.11.003

Behie SW, Bidochka MJ (2014) Nutrient transfer in plant-fungal symbioses. Trend Plant Sci 19(11):734-740. https://doi.org/10.1016/j.tplan ts.2014.06.007

Bonfante P, Genre A (2010) Mechanisms underlying beneficial plant-fungus interactions in mycorrhizal symbiosis. Nat Commun 1:48. https://doi. org/10.1038/ncomms1046

Cairney JWG (2012) Extramatrical mycelia of ectomycorrhizal fungi as moderators of carbon dynamics in forest soil. Soil Biol Biochem 47:198-208. https ://doi.org/10.1016/j.soilbio.2011.12.029

Chen PL, Zhao ML, Tang F, Hu YM, Peng XJ, Shen SH (2019) The effect of environment on the microbiome associated with the roots of a native woody plant under different climate types in China. Appl Microbiol Biot 103(9):3899-3913. https://doi.org/10.1007/s00253-019-09747-6 
Courty PE, Buée M, Diedhiou AG, Frey-Klett P, Le Tacon F, Rineau F, Turpault MP, Uroz S, Garbaye J (2010) The role of ectomycorrhizal communities in forest ecosystem processes: New perspectives and emerging concepts. Soil Biol Biochem 42(5):679-698. https://doi.org/10.1016/j.soilbio.2009.12.006

Daza A, Manjon JL, Camacho M, Romero de la Osa L, Aguilar A, Santamaria C (2006) Effect of carbon and nitrogen sources, $\mathrm{pH}$ and temperature on in vitro culture of several isolates of Amanita caesarea (Scop.:Fr.) Pers. Mycorrhiza 16:133-136. https://doi.org/10.1007/s00572-005-0025-6

Duñabeitia MK, Hormilla S, García-Plazaola Jl, Txarterina K, Arteche U, Becerril JM (2004) Differential responses of three fungal species to environmental factors and their role in the mycorrhization of Pinus radiata D. Don. Mycorrhiza 14:11-18. https://doi.org/10.1007/s00572-003-0270-5

de Zelicourt A, Al-Yousif M, Hirt H (2013) Rhizosphere microbes as essential partners for plant stress tolerance. Mol Plant 6(2):242-245. https://doi. org/10.1093/mp/sst028

Garcia K, Doidy J, Zimmermann SD, Wipf D, Courty PE (2016) Take a trip through the plant and fungal transportome of mycorrhiza. Trends Plant Sci 21(11):937-950. https://doi.org/10.1016/j.tplants.2016.07.010

Guerrero-Galán C, Calvo-Polanco M, Zimmermann SD (2019) Ectomycorrhizal symbiosis helps plants to challenge salt stress conditions. Mycorrhiza 29:291-301. https://doi.org/10.1007/s00572-019-00894-2

Hoagland DR, Arnon DI (1950) The water culture method for growing plants without soil. Coll Agric UC Berkeley. USA Cal Agric Exp Stn Circ 347:1-32

Hossain MM, Sultana F, Islam S (2017) Plant growth-promoting fungi (PGPF): Phytostimulation and induced systemic resistance. In: Singh DP, Singh HB, Prabha R (eds) Plant-microbe interactions in agroecological perspectives. Springer, Singapore, pp 135-191. https://doi. org/10.1007/978-981-10-6593-4_6

Javeria S, Kumar V, Sharma P, Prasad L, Kumar M, Varma A (2017) Mycorrhizal symbiosis: Ways underlying plant-fungus interactions. In: Varma A, Prasad R, Tuteja N (eds) Mycorrhiza-eco-physiology, secondary metabolites, nanomaterials. Springer, Cham. https://doi.org/10.1007/978-3-319-57849 -1 10

Kulkarni S, Dhakar K, Joshi A (2019) Alkaliphiles: diversity and bioprospection. In: Das S, Dash HR (eds) Microbial diversity in the genomic era. Academic Press, Cambridge, pp 239-263

Kumar A, Verma JP (2018) Does plant-Microbe interaction confer stress tolerance in plants: A review? Microbiol Res 207:41-52. https://doi. org/10.1016/j.micres.2017.11.004

Lazarević J, Stojičić D, Keča N (2016) Effects of temperature, pH and carbon and nitrogen sources on growth of in vitro cultures of ectomycorrhizal isolates from Pinus heldreichii forest. Forest Syst 25(1):e048. https://doi. org/10.5424/fs/2016251-07036

Leroy C, Maes AQ, Louisanna E, Sejalon-Delmas N (2019) How significant are endophytic fungi in bromeliad seeds and seedlings? Effects on germination, survival and performance of two epiphytic plant species. Fungal Ecol 39:296-306. https://doi.org/10.1016/j.funeco.2019.01.004

Liu BH, Liu XH, Liu FC, Ma HL, Ma BY, Zhang WX, Peng L (2019) Growth improvement of Lolium multiforum Lam. induced by seed inoculation with fungus suspension of Xerocomus badius and Serendipita indica. AMB Express 9:145. https://doi.org/10.1186/s13568-019-0865-7

Murillo-Amador B, Lopez-Aguilar R, Kaya C, Larrinaga-Mayoral J, Flores-Hernandez $\mathrm{A}$ (2002) Comparative effects of $\mathrm{NaCl}$ and polyethylene glycol on germination, emergence and seedling growth of cowpea. J Agron Crop Sci 188:235-247. https://doi.org/10.1046/j.1439-037X.2002.00563.x

Murphy BR, Doohan FM, Hodkinson TR (2017) A seed dressing combining fungal endophyte spores and fungicides improves seedling survival and early growth in barley and oat. Symbiosis 71(1):69-76. https://doi. org/10.1007/s13199-016-0418-7

Navarro-Ródenas A, Lozano-Carrillo MC, Pérez-Gilabert M, Morte A (2011) Effect of water stress on in vitro mycelium cultures of two mycorrhizal desert truffles. Mycorrhiza 21(4):247-253

Owen D, Williams AP, Griffith GW, Withers PJ (2015) Use of commercial bioinoculants to increase agricultural production through improved phosphrous acquisition. Appl Soil Ecol 86:41-54. https://doi.org/10.1016/j. apsoil.2014.09.012

Petrović $G$, Jovičić $D$, Nikolić $Z$, Tamindžić G, Ignjatov M, Milošević D, Milošević B (2016) Comparative study of drought and salt stress effects on germination and seedling growth of pea. Genetika 48:373-381. https:// doi.org/10.2298/GENSR1601373P

Prasad SR, Kamble UR, Sripathy KV, Bhaskar KU, Singh DP (2016) Seed bio-priming for biotic and abiotic stress management. In: Singh DP, Singh HB, Prabha R (eds) Microbial inoculants in sustainable agricultural productivity. Springer, New Delhi, pp 211-228. https://doi. org/10.1007/978-81-322-2647-5

Qin Y, Pan XY, Kubicek C, Druzhinina I, Chenthamara K, Labbé J, Yuan ZL (2017) Diverse plant-associated pleosporalean fungi from saline areas: ecological tolerance and nitrogen-status dependent effects on plant growth. Front Microbiol 8:158. https://doi.org/10.3389/fmicb.2017.00158

Shen Q, Liu YY, Naqvi NI (2018) Fungal effectors at the crossroads of phytohormone signaling. Curr Opin Microbiol 46:1-6. https://doi.org/10.1016/j. mib.2018.01.006

Siri-in J, Kumla J, Suwannarach N, Lumyong S (2014) Culture conditions and some properties of pure culture of ectomycorrhizal fungus, Scleroderma sinnamariense. Chiang Mai J Sci 41(2):275-285

Species Fungorum (2019) http://www.speciesfungorum.org/Names/SynSp ecies.asp?RecordID=550569. Accessed 26 Aug 2019

Tan XM, Wang CL, Chen XM, Zhou YQ, Wang YQ, Luo AX, Liu ZH, Guo SX (2014) In vitro seed germination and seedling growth of an endangered epiphytic orchid, Dendrobium officinale, endemic to China using mycorrhizal fungi (Tulasnella sp.). Sci Hortic 165:62-68. https://doi.org/10.1016/j.scien ta.2013.10.031

Tang M, Sheng M, Chen H, Zhang FF (2009) In vitro salinity resistance of three ectomycorrhizal fungi. Soil Biol Biochem 41(5):948-953. https://doi. org/10.1016/j.soilbio.2008.12.007

Taylor AFS, Alexander I (2005) The ectomycorrhizal symbiosis: Life in the real world. Mycologist 19(3):102-112. https://doi.org/10.1017/S0269915X0 5003034

Tomer S, Suyal DC, Goel R (2016) Biofertilizers: A timely approach for sustainable agriculture. In: Choudhary DK, Varma A, Tuteja N (eds) Plant-microbe interaction: An approach to sustainable agriculture. Springer, Singapore, pp 375-395. https://doi.org/10.1007/978-981-10-2854-0

Vijayabharathi R, Sathya A, Gopalakrishnan S (2016) A renaissance in plant growth promoting and biocontrol agents by endophytes. In: Singh DP, singh HB, Prabha R (eds) Microbial inoculants in sustainable agricultural productivity. Springer, New Delhi, pp 37-60. https://doi. org/10.1007/978-81-322-2647-5

Vimal SR, Singh JS, Arora NK, Singh S (2017) Soil-plant-microbe interactions in stressed agriculture management: a review. Pedosphere 27(2):177-192. https://doi.org/10.1016/S1002-0160(17)60309-6

Xu ML, Zhu JJ, Kang HZ, Xu AH, Zhang JX, Li FQ (2008) Optimum conditions for pure culture of major ectomycorrhizal fungi obtained from Pinus sylvestris var. mongolica plantations in southeastern Keerqin sandy lands, China. J Forestry Res 19(2):113-118. https://doi.org/10.1007/s1 167 6-008-0019-2

Yan L, Zhu J, Zhao XX, Shi JL, Jiang CM, Shao DY (2019) Beneficial effects of endophytic fungi colonization on plants. Appl Microbiol Biot 103(8):3327-3340. https://doi.org/10.1007/s00253-019-09713-2

Zhang H, Irving $\sqcup$, McGill C, Matthew C, Zhou D, Kemp P (2010) The effects of salinity and osmotic stress on barley germination rate: sodium as an osmotic regulator. Ann Bot 106:1027-1035. https://doi.org/10.1093/aob/ mcq204

Zhang $H$ H, Tang M, Yang $Y$ (2011) The response of ectomycorrhizal (ECM) fungi under water stress induced by polyethylene glycol (PEG) 6000. Afr J of Microbiol Res 5(4):365-373

Zhu JJ, Li FQ, Xu ML, Kang HZ, Wu XY (2008) The role of ectomycorrhizal fungi in alleviating pine decline in semiarid sandy soil of northern China: an experimental approach. Ann For Sci 65(3):304. https://doi.org/10.1051/ forest:2008007

\section{Publisher's note}

Springer Nature remains neutral with regard to jurisdictional claims in published maps and institutional affiliations. 